\title{
Case Study Experiment: A Toolkit to Drive Cultural Change
}

\author{
https://doi.org/10.3991/ijac.v12i1.9471 \\ Lorinda Faye Lewis $\left({ }^{\bowtie}\right)$ \\ Charter Oak State College, USA \\ llewis @gpsedge.com
}

\begin{abstract}
Both private and public sectors are ready for a new management model that engages the workforce. Necessitated by the baby boomer retirements rates, lower unemployment, an increased demand for skilled and unskilled labor, and the newest generation in the employment pool, companies have a need to create cultures that attract and retain talent like never before. As a result, a variety of new books, articles, and theories have been introduced to the body of knowledge, including concepts to attempt to change the organizational culture. This case study demonstrates an experiment conducted in a Fortune 500 company, integrating theories and practices from a variety of domains to improve the team culture and ultimately business performance. The tools and techniques are offered for replication.
\end{abstract}

Keywords - Employee engagement, empowerment, culture, people centered cultures, organizational design, organizational behavior, job satisfaction factors, employee morale.

\section{Introduction}

The concept of employee engagement is not new to those in the management field. In the academic literature, employee engagement, job satisfaction factors, employee retention, morale, and culture are so densely intertwined it is seemingly impossible to dissect them into distinct bodies of knowledge (Kim, Kim, Woo, Park, Jo, Park, \& Lim, 2017). The topic is found embedded in the domains of management, organizational psychology, adult learning theory, leadership, organizational behavior, operational excellence, and more. Understanding employees - people - has become an industry in and of itself. There is no shortage of content for a would-be practitioner to sort through in an effort to make a difference in their organizational culture or team dynamics.

Some believe we are at the crossroads of a new change of age, with a need to focus on the workforce as a family (Chapman \& Sisodia, 2015), creating self-directed work teams that operate like a community rather than a hierarchy (Appelo, 2016; Laloux, 2014) with distributed decision making (Marquet 2014; Robertson, 2015) and a focus on each employee's unique intrinsic motivation (Appelo, 2011; Appelo, 2016; Pink, 2011; Senge, 2015). This new perspective of leadership and management also requires 
new organization structures (Appelo, 2011; Appelo, 2016; Laloux, 2014; Robertson, 2015).

\section{Concepts}

Job satisfaction factors were identified in 1935 in the book Job Satisfaction written by Robert Hoppock. Vroom (1962) explained that when employees were personally involved in the work they were performing, they had higher job satisfaction (Lewis \& Wescott, 2017). In this action research pilot project, a corporate team experimented with a variety of new tools to see if employee engagement could be measurably improved.

\section{A History of Management and Leadership Models}

Although the literature is rife with content, this section highlights some of the most notable research, publications, methods, and scholars associated with the historical transformation of society's changing perspective on leadership and management. Each of these seminal concepts caused a significant shift in our thinking and practices that led us to the business environment we operate in today. This literature review offers a primer through a journey of management and leadership models.

Frederick Taylor is touted to have invented the concept of management, using the scientific method, measuring the performance of every employee to the designated time allotted for the task (Kanigel, 2005). In this paradigm, employees were not permitted to engage or offer suggestions and were relegated to a lower position in the organization, elevating managers to center stage with tools to measure and hold employees to account (Kanigel, 2005). Taylor's publication of The Principles of Scientific Management (1929) ushered in the management model now referred to as Taylorism which persisted in organizations as late as the 1940s (Kanigel, 2005).

In the 1940s a management shift from Taylorism resulted from the now infamous Hawthorne Studies in 1932 which began to explore the human condition in relation to physical conditions of the workplace (Pirson \& Lawrence, 2010). Kurt Lewin, notable social scientist, introduced concepts related to change theory, action research, and action learning among other contributions, which later became branded Organizational Development (King, 2005). Trist introduced the theory of Sociotechnical Systems, making a complete divergence from Taylorism, identifying the workplace as a set of systems with people and technology structures that need to support one another for efficiency, productivity, and job satisfaction (Long, 2013; Newton, Long \& Sievers 2006).

The decade of the 1950s was transformational to business as research began to truly uncover the human condition and the impact the work has on our daily lives. In this era, we were introduced to Maslow's Hierarchy of Needs, Peter Drucker's concepts of motivating and developing people, and Frederick Herzberg's hygiene factors, directly translating Maslow's concepts to the workplace to enhance employee performance (Appelo, 2011). These works have stood the test of time as they are still commonly 
referred to and held in high regard in business literature and in management practices that exist today.

The 1960's led us through Theory X and Y in McGregor's The Human Side of Enterprise which guided industry to institutionalize standard personnel policies and practices to manage employees along a modified package of Maslow's Hierarchy of Needs (Heil, Bennis, \& Stephens, 2000). Likewise, Blake and Mouton (1964) developed a management grid that defined two necessary leadership behaviors depicted on two dimensions with axes of concern for people and concern for task (Van De Vliert \& Kabanoff, 2017).

The 1970s and 1980's highlight the work of Tom Gilbert (1978) and Tom Peters (1978) who each contributed to the integration of continuous process improvement and employee performance metrics and standards. Both authors asserted the need for performance requirements linked to process performance and started a new era of management consulting firms.

The business excesses and successes of the 80's generated a world of successful management consultants, new research, new paradigms, and management models that directly led to the proliferation of 1990's. Among those are Jim Womack, John Shook, and others who learned from the management philosophy of the Japanese manufacturers and introduced the lean management system resulting from work introduced by Deming and practiced at Toyota (Lewis \& Wescott, 2017). The management movement was focusing on quality and continuous improvement of business processes and rewarding people for their engagement in those activities. Changing technologies resulted in new concerns around ethics and compliance.

In the 2000s, we find the work of Peter Senge, The Fifth Discipline, that introduced metanoia and the concept of a learning organization with the best leaders being those who ask questions and learn with the team members, acting more as facilitators than rulers. Daniel Pink (2009) built on this work and began to look at the importance of aligning and promoting work with intrinsic motivators rather extrinsic.

This new change of age seems to be in a fledging stage now, with examples of a new way of managing, leading, and organizing companies proliferating the bookshelves and academia alike. Laloux (2014) built on the work of Beck and Graves and others to introduce a philosophy of organizational maturity as categorized by colors. The most mature organizations, demonstrating self-direct work teams and distributed decision making are identified at teal (Laloux, 2014). We have examples of new startups opting out of the existing organizational paradigms, instead creating organizations that are holacracies, autonomous teams with decision making authority, operating as a community invested in the success of the team (Laloux, 2014; Robertson, 2015). To achieve teal, the highest level of maturity in this new organizational paradigm, there are three primary targets: evolutionary purpose, self-management, and wholeness. These levels align with developmental evolution of consciousness addressed in research by Abraham Maslow and Clare Green (Laloux, 2014; Robertson, 2015).

Laloux (2014) reflects to the works of Beck and Cowan Spiral Dynamics (1996) and the concept of creating a community within our companies that focus on social values rather than the individual, with everyone having an equal voice. This kind of culture may not fit everywhere, but certainly steps toward that goal will create a better 
organizational culture. There is little doubt that improved cultures result in improved business performance (Chapman \& Sisodia, 2015).

Appelo $(2011,2016)$ offered a variety of tools, games, and practices also leveraging distributed decision making and concepts of intrinsic motivation to bring more happiness into the work center. Many of these games, tools, and methodologies were incorporated in this experiment.

\section{Pilot Program}

A cohesive team of 18 employees ( 10 female, 8 male) of a publicly traded company set out to experiment with some of the tools touted to improve morale, increase engagement, and build team member trust. Two members of the team were geographically separated, participating virtually and traveling in for some activities. The team members ranged in tenure with the company from three days to ten years.

Gallup's $Q^{12}$ employee engagement survey (Gallup, 2018) was selected as the measurement tool. A pre-project survey was conducted to establish a baseline score and to identify the lowest scoring areas to focus the improvement project activities around. The results were documented and reviewed as a team with a neutral, third party facilitator who documented the pilot program and performed this action research.

The tools used in this pilot were determined based on research conducted in a 30day period to search for activities techniques to drive cultural change, specifically around the lowest $\mathrm{Q}^{12}$ category scores. The selected tools were presented to the team. The activities deployed and recorded according to the plan and ran for a total of seven months. Five key metrics were the focus of this experiment based on the results of the Gallup $\mathrm{Q}^{12}$ :

1. Diversity and inclusion (D\&I): How did the team feel about opportunities for D \& I candidates - baseline $85 \%$

2. Morale: How did the team feel about working in the department -baseline $77 \%$

3. Professional Development: How did the team feel about growth opportunities in the department-baseline $75 \%$

4. Onboarding satisfaction: How did new hires rate our onboarding process: baseline $82 \%$

5. Communication: How transparent were the communications between team members- baseline $50 \%$

Additional measures included dimensions of trust, participation in leading events, and general employee engagement.

The team were introduced to 15 potential tools, games, and practices touted by the research. They selected just nine to begin their experiment. The following section will review the nine tools and practices that were implemented during this experiment.

\subsection{Kirton Adaption-Innovation (KAI) Instrument}

Although a variety of psychometric measures were considered, the team selected the Kirton Adaption-Innovation (KAI) inventory as it was supported with over 50 years of academic published work to include correlation and reliability data (Buffington \& 
Jablokow, 2015; Stum, 2009). This 33-question instrument determines the cognitive problem-solving style of respondents. The team hired a certificated practitioner to administer the instrument and facilitate a three-hour workshop. The workshop revealed their KAI results and helped the team understand the cognitive gaps between team members. As a result, they discovered the interpersonal variances between the preferred cognitive problem-solving style and strategies to engage in a more harmonious fashion (Stum, 2009). Each team member learned their place on a continuum between highly adaptive and highly innovative and how these cognitive gaps could influence team dynamics.

\subsection{Monthly Surveys}

The team selected to use the Gallup's $Q^{12}$ employee engagement survey (Gallup, 2018) and to respond to monthly surveys to provide a continuous flow of measures related to the progress the activities were having on the metrics. This offered an opportunity to see if activities were having generating the desired impact, if team members found value in them, and if any changes needed to be made.

\subsection{Daily Climate Check}

In search of a way to rapidly collect data, the team devised a daily climate check with a remarkably simple process. A red plastic box and a green plastic box were mounted near the door to the department. Each Monday, the team leader issued five poker chips to each team member. Daily, team members would drop their poker chip into the green box if they had enjoyed working in the department on that day. If they had not enjoyed their day, they entered the chip in the red box along with a color-coded note that helped to identify the reason. These cards, mounted near the red box, offered with a color legend for easy access and selection. Some of the reasons were:

- Too much work - felt overloaded

- Inefficient meetings

- Something outside of the team control but inside the organization (another team, etc.)

- $\quad$ Something outside of the organization (a family issue, etc.)

This activity was intended to help refine the morale measure to understand if there were any changes within the control of the department.

\subsection{Gratitude Board}

A laminated board was mounted in the conference room with the image of a bucket and the header Have you filled someone's bucket today? This was an idea the team had after reading How Full is Your Bucket (Rath \& Clifton, 2005). A box of adhesive notes mounted beside the board provided an easy opportunity to jot down the note and stick it to the board. Employees were encouraged to fill out a note when someone on the team went beyond expectations on a work-related item or a personal item. These notes 
were read aloud during each team meeting and distributed to the person identified. The activity of expressing gratitude is uplifting for the giver even more than the receiver (Rath \& Clifton). At the team meetings, each of the notes were removed, read aloud, and handed to the recipient, providing an avenue for recognition in front of the team.

\subsection{Celebration Grid}

A celebration grid was mounted on a wall of the conference room. A training event introduced the purpose and the team determined the frequency of review. A celebration grid (Appelo, 2016) helps team members recognize failures and the learning that occurs from them. Learning from failure is a key concept found in lean, agile, and many other programs but Appelo (2016) offered a straightforward way to think about which failures were worthy of celebration and how to recognize failures you should not celebrate. The greatest learning from failure occurs when a team member finds a new concept and experiments with it, knowing there is a 50-50 chance of success in making an improvement. This research project itself fits this definition.

\subsection{Moving Motivators}

Considering the content from Laloux (2014), Pink (2011), and Appelo (2016) a variety of tools were used to understand each team member's intrinsic motivation. Appelo (2016) offered a deck of 10 cards for team members to rank according to their own motivations. The cards represent categories such as status, freedom, honor, mastery, and other topics that align with intrinsic motivation. The participants organize the cards in the sequence of importance to them in general. The facilitator then introduces an organizational change situation that might occur and ask the participants to adjust the sequence based on this new change. This activity quickly demonstrated the power of the simple exercise. The participants each shared that is was an enlightening process. Team members were encouraged to share their experience with the team explore commonality and differences.

\subsection{Team Boards and Toyota Kata}

Team boards were mounted in a conference room to create a location for the team to congregate and discuss progress on the experiments and the results of the monthly surveys. These boards and the review cycles conducted every monthly and followed the kata coaching model (Rother, 2010). This model encourages the concept of leader as coach, with leaders asking a routine set of questions in the same sequence at each meeting. The kata coaching cards were used to help the team create a standard routine for each meeting. The questions encourage the team member to begin to think differently about their work. This kind of structured review cycle encourages team members to learn to apply the scientific approach to their work, learn a coaching skill, and stabilize the reporting of results.

\subsection{Quarterly Team Offsites}


Quarterly, one-day, local offsite meetings were scheduled and prioritized with specific agendas. Each session included routine business topics like strategy deployment progress, project changes since the last session, and business updates. In addition, updates on all experimental activities and their impact on the measures were shared and as a team, they decided on activities to start, stop, or continue to impact the engagement metrics. Additionally, new learning and celebration was a recurring agenda item. The team celebrated birthdays, graduations, and other important team member topics.

Upon conclusion of the project, the team conducted a session to gather information related to the lived experience of the team members which aligned with phenomenological research techniques (Moustakas, 1994). This information was critical to understanding which activities were perceived to be most influential in the marked improvement in the scores.

\subsection{World Café Facilitation Model}

The technique of world café technique (World Café Community Foundation, 2015) was used as the facilitation model. This model assigned topics to breakout tables and allowed all team members to rotate multiple times through each table, capturing their thoughts and ideas related to each topic. Table topics were a) Which activity had the greatest impact on you and why? b) Do you feel more connected to your team members now? c) What could we have done differently? D) Which activities do you wish to continue doing after the program ends?

\section{$5 \quad$ Pilot Program Results}

Throughout the pilot program, the scores improved each month. Upon completion of the pilot, measures were compared to the baseline scores and the results were clear:

1. Diversity dimension improved from $85 \%$ to $92 \%$

2. Morale dimension improved from $77 \%$ to $100 \%$

3. Professional Development (Growth) dimension improved from $75 \%$ to $96 \%$

4. Onboarding dimension improved from $82 \%$ to $100 \%$

5. Communication dimension improved from $50 \%$ to $85 \%$

At the end of the pilot program, June 2018, a final World Café session was facilitated to collect their perceptions of the program. The team identified the following list of benefits of each of the activities and how they contributed to the measures:

\subsection{Kirton Adaption-Innovation (KAI) Instrument}

1. Diversity: Helped the team understand diversity is not just race, religion, or sex, but including and respecting diversity of thought and approach to problem-solving helps the team be more effective.

2. Morale: Team members had a better understanding of each other and a newfound common ground that improved the interpersonal relationships. 
3. Professional development: Team members found new techniques to engage co-workers with whom they once felt conflict.

4. Onboarding: N/A. Because no new hires joined the team after the KAI session was conducted, we cannot attribute improvement in this dimension to the use of KAI.

5. Communication: Team members reflected the KAI explained the tension they felt with some other employees and gave them techniques to improve communications and therefore relationships and project execution.

\subsection{Daily Climate Check}

1. Diversity: Helped the team understand that everyone is different, with various factors that influence their perception of a good or bad day.

2. Morale: Required the team members to reflect and understand why they were having a good or bad day and assign the cause appropriately.

3. Professional development: The reflection activity required them to face the situations that were driving their mood and assign the cause appropriately, rather than just saying they had a bad day.

4. Onboarding: New hires integrated into the team culture quickly as they learned the causes of reported good or bad days.

5. Communication: Team members reported changing their own behaviors, being more friendly, supportive, and communicative to help team members report more good days.

\subsection{Gratitude Board}

1. Diversity: Demonstrated everyone was contributing, in some way, to improve the culture.

2. Morale: Employees who drafted the kudos were more positive after writing them down and after hearing them read aloud to the recipient. Recipients began collecting their notes of recognition and posting them in their offices as coveted awards, worthy of display. Team members worked to create encounters where others would document their contribution, so they could be recognized each week.

3. Professional development: Developed the skill of complimenting and thank people for their contribution to the team success.

4. Onboarding: New hires integrated into the team culture quickly as they learned the behaviors that made the team a cohesive, highly functioning group.

5. Communication: Team members changed behaviors, asking how they could help. They learned how to recognize and be recognized in a public setting, some had reported being uncomfortable in both roles at the onset of the pilot.

\subsection{Celebration Grid}


The celebration grid was the least utilized tool of the program for a few reasons. It was the last activity introduced to the pilot and never really gained traction. The team reflected on how it could have been used to drive professional development and new learning, if they had embraced it more holistically.

\subsection{Moving Motivators}

1. Diversity: Helped the team understand the diversity of the team, recognizing that they were each motivated by various aspects of the work and the environment. When a change occurred, some team members inspired, and others were dispirited

2. Morale: Team members understood themselves and their team members better, improving relationships.

3. Professional development: Team members recognized what was important to them and began to reflect on and appreciate elements of their work and the team culture that aligned with their most important intrinsic motivations.

4. Onboarding: New hires enjoyed the activities as it allowed them to quickly understand their new teammates, the culture of the organization, and how those things aligned with their own intrinsic motivations.

5. Communication: The recognition of how different the team members were in regard to their motivations offered a new way to communicate with one another. It also provided an opportunity to collaborate on team projects differently, transferring tasks that aligned better with another team member's motivation.

\subsection{Team Boards and Toyota Kata}

1. Diversity: The team identified this technique was a way to level set the great diversity of learning styles as well as experience levels and provided a great platform for learning.

2. Morale: Team members reported feeling a growing sense of pride as they developed this new skill.

3. Professional development: Team members recognized this new technique as a leadership technique that they would be able to use throughout their career. Several reported exporting this technique to other areas of their work and even into their family engagements.

4. Onboarding: New hires benefited by understanding how to think about their new work and reported learning their new roles quickly because of the Kata questioning technique.

5. Communication: The team reported the impact of the kata technique as instrumental in developing a new way to listen to and report out progress status.

\subsection{World Café Facilitation Model}


1. Diversity: The team identified this technique was beneficial in engaging all team members to provide feedback, regardless of their experience levels, tenure with the company, or personality. It provided a collaborative and safe way to share ideas.

2. Morale: Team members reported they felt the collaborative nature of the activity helped them get to know one and understand another better.

3. Professional development: Team members reported this as a technique that they could easily replicate and use throughout their career.

4. Onboarding: New hires benefited by listening to and collaborating with their new team members, quickly getting to know people and the importance of their work.

5. Communication: The collaborative nature of the activity supported communication and built rapport quickly, with a spill over into daily communication activities.

\section{$6 \quad$ Participant Testimonials}

Team members were also encouraged to provide feedback on the pilot program in totality, offering insight into their lived experience during the seven-month experiment.

Participant 1 said, "I really enjoyed the team offsites, especially the one when we were allowed to bring our family. That helped me get to know everyone so much better."

Participant 3 said, "I feel like I know my teammates on a much deeper level now. It was a great experiment! Now I feel more connected, which I think is the same as trust. I know them so much better now so I'm more comfortable trusting them."

Participant 6 said, "Understanding my internal motivations with the cards was eyeopening for me. I have talked about it with my family as well and tried to walk them through the game myself. We are still talking about our motivators six months later! It has really helped me focus on what matters to me and understand why that is important."

Participant 7 reported, "I think the gratitude board was so simple but had a great impact. It not only gave us a chance to recognize each other, we got to hear about projects people were working on and how they helped each other be successful."

Participant 9 said, "I liked everything about our project but if I had to pick one thing I'd have to say learning about kata coaching and meeting with the team regularly was my favorite. I started using the technique at home with my kids. It has eliminated some of the chaos of my home life which is amazing."

Participant 14 said, "The KAI session was amazing! It helped me understand so many of the frustrations I was having with certain people at work. Now we can openly laugh and say well we know you are more adaptive than I am and then we are on the same page again.” 


\section{Conclusion}

We are in an era of change related to management, leadership, and organizational designs that will be a difficult transition for many companies that are mired in historical hierarchies and models. The need for practices and techniques that are simple to institutionalize, respectful of team member's time, and effective will be in great demand. Preparing a toolkit of repeatable practices that busy managers can deploy rapidly will help in the cultural shift necessary to be an employer of choice and increase retention.

The results of this pilot program demonstrate how the tools and techniques can quickly improve employee morale, perception of their team, and ultimately their commitment to the organization. Activities that build rapport, break down barriers, and help people connect to one another result in higher team effectiveness. This combination of activities contributed to the significant improvement in the employee engagement metrics.

As organizations seek their competitive advantage, they now must not only consider competitors in their market, they also must consider competitors for their workforce. Appelo (2011), Laloux, (2014), and Robertson, (2014) are some of the new voices that are encouraging this change of age related to organizational culture. They challenge organizations to think differently, to create holacracies where organizations behave like communities, focusing on the greater good, social values, what is best for their employees, what can make a difference in their lives and the communities, with everyone having an equal voice.

While it is unlikely that most organizations will achieve the elusive title of a teal organization, the incremental pursuit is a worthwhile effort that will create better cultures, improve employee morale, and engagement. Improved business results are clear when employee morale and engagement are increased (Chapman \& Sisodia, 2015; Marquet, 2012). Retention is increased as well, a necessity in the current state mass exodus of baby boomers and a shortage of eligible workforce in so many industries and areas of our country (Bartash, 2018; Kim, et.al, 2017).

\section{$8 \quad$ References}

[1] Appelo, J. (2011). Management 3.0: Leading agile developers. Developing agile leaders. Boston: Pearson

[2] Appelo, J. (2016). Managing for happiness. Games, tools, and practices to motivate any team. Hoboken, NJ: Wiley

[3] Bartash, J. (2018). Screaming labor shortage forcing firms to get creative to fill record job openings. Marketwatch. Retrieved from https://www.marketwatch.com/story/screaminglabor-shortage-forcing-firms-to-get-creative-to-fill-record-job-openings-2018-07-18

[4] Buffington, K. W., Jablokow, K. W. \& Martin, K. A. (2015). Project Team Dynamics and Cognitive Style. Engineering Management Journal, 14(3), 25-33. https://doi.org/10.1080/10429247.2002.11415170

[5] Chapman, R. \& Sisodia, R. (2015). Everybody matters: The extraordinary power of caring for your people like family. NY: Penguin 
[6] Gallup (n.d.). Gallup Q12 employee engagement survey. Retrieved from https://q12.gallup.com/Public/de-de/Features

[7] Heil, G., Bennis, W., \& Stephens, D. C. (2000). Douglas McGregor, Revisited: Managing the Human Side of the Enterprise. NY: Wiley \& Sons

[8] Hoppock, R. (1935). Job Satisfaction. NY: Harper \& Bros.

[9] Kanigel, R. (2005). The one best way: Frederick Winslow Taylor. MIT Press: Cambridge, MA

[10] King, L. D. (2005). Lewin revisited: A perspective on his contribution through video archives, the literature, and interview of subject matter experts (Order No. 3169639). Available from ProQuest Dissertations \& Theses Global. (305348898).

[11] Laloux, F. (2014). Reinventing Organizations: A Guide to Creating Organizations Inspired by the Next Stage of Human Consciousness. Brussels: Nelson Parker

[12] Lenhart, J. G. (2018). Personal communications.

[13] Lewis, L. F., \& Wescott, H. D. (2017). Multi-generational workforce: Four generations united in lean. Journal of Business Studies Quarterly, 8(3), 1-14. Retrieved from https://jbsq.org/

[14] Long, S. (2013). Socioanalytic Methods: Discovering the Hidden in Organisations and Social Systems. ED Susan Long NY: Karnac. https://doi.org/10.4324/9780429480355

[15] Marquet, L. D. (2012). Turn the ship around! A true story of turning followers into leaders. NY: Penguin

[16] Newton, J., Long, S., \& Sievers, B. (Eds.). (2006). Coaching in depth: The organizational role analysis approach. London: Karnac

[17] Pink, D. H. (2011). Drive. The surprising truth about what motivates us. NY: Riverhead

[18] Pirson, M. A., \& Lawrence, P. R. (2010). Humanism in business - towards a paradigm shift? Journal of Business Ethics, 93(4), 553-565. https://doi.org/10.1007/s10551-009-0239-1

[19] Rath T. \& Clifton, D. O. (2004). How full is your bucket? NY: Gallup

[20] Redlener, J. (1948). A comparative study of the efficiency of the Kuder Preference Record and the Strong Vocational Interest Blank in the prediction of job satisfaction. Proquest Dissertations. Available from ProQuest Dissertations \& Theses Global. (1655001103). Retrieved from https://search-proquestcom.proxy2.ncu.edu/docview/1655001103?accountid=139631

[21] Robertson, B. J. (2014). Holacracy: The new management system for a rapidly changing world. NY: Henry Holt

[22] Rother, M. (2010). Toyota kata. Managing people for improvement, adaptiveness, and superior results. NY: McGraw-Hill

[23] Senge, P. (2015). What is metanoia? [Video file]. Retrieved from $\mathrm{https}: / /$ www.youtube.com/watch? $\mathrm{v}=4 \mathrm{RBtBAAdt} 20$

[24] Stum, J. (2009). Kirton's adaption-innovation theory: Managing cognitive styles in times of diversity and change. Emerging Leadership Journeys. 2(1), 66-79. Retrieved from https:/www.regent.edu/acad/global/publications/elj/

[25] Van De Vliert, E. \& Kabanoff, B. (2017). Toward theory-based measures of conflict management. Academy of Management, 33(1), https://doi.org/10.5465/256359

[26] Vroom, V. H. (1962). Ego-involvement, job satisfaction, and job performance. Personnel Psychology, 15(2), 159-177. https://doi.org/10.1111/j.1744-6570.1962.tb01858.x

[27] Kim, W., Kim, J., Woo, H. Park, J., Jo, J., Park, S. H. \& Lim, S. Y. (2017). The relationship between work engagement and organizational commitment: Proposing research agendas through a review of empirical literature. Human Resource Development Review, 16(4), 350 -376. https://doi.org/10.1177/1534484317725967 
[28] World Café Community Foundation. (2015). A quick reference guide for hosting world café. Retrieved from http://www.theworldcafe.com/wp-content/uploads/2015/07/Cafe-ToGo-Revised.pdf

\section{Authors}

Lorinda Faye Lewis Dr. Lewis is a scholar-practitioner, established in a wide variety of disciplines and areas of business. She has a passion for leading and developing others. She has accumulated her perspective through an unusual career trajectory that includes her experiences as a retired Air Force logistician, a continuous improvement and P\&L executive of a Fortune 500 company, an adjunct professor at universities, and as a pro bono continuous improvement coach for Collective Impact Initiatives with not-for-profit agencies. She is a prominent public speaker and published academician who can translate complex ideas into relatable stories to inspire audiences of all levels. As a public speaker, she is in high demand at national and international academic and industry conferences as well as corporate leadership events. As a professional coach, she facilitates mentor circles, coaching teams through leadership topics and offers one-on-one professional development mentoring and is certificated to administer the Kirton Adaption-Innovation Inventory. As an adjunct faculty member at two universities, she teaches courses on lean, change management, coaching and mentoring for business, marketing, and global business strategy.

Article submitted 2018-09-02. Resubmitted 2019-01-22. Final acceptance 2019-01-25. Final version published as submitted by the authors. 